\title{
TA'RIB (ARABISASI) ISTILAH-ISTILAH BUDAYA DALAM MAJALAH ALO INDONESIA
}

\author{
TA'RIB (ARABISATION) CULTURE TERMS IN \\ ALO INDONESIA MAGAZINE
}

\author{
Syaifullah \\ Universitas 'Aisyiyah (UNISA) Yogyakarta \\ Jl. Siliwangi (Ringroad Barat) No. 63 Mlangi, \\ Nogotirto, Gamping, Sleman, Yogyakarta, 55292 \\ e-mail: syaifullah366@gmail.com \\ DOI: $10.36424 / j p s b . v 6 i 1.162$
}

Naskah Diterima: 04 April 2020 Naskah Direvisi: 02 Mei 2020

Naskah Disetujui: 06 Mei 2020

\begin{abstract}
Abstrak
Majalah Alo Indonesia merupakan majalah berbahasa Arab yang memuat banyak informasi keanekaragaman budaya Indonesia. Sebagai majalah berbahasa Arab banyak ditemukan kosa kata yang tidak ada padanannya dalam bahasa Arab sehingga diperlukan adanya ta'rib (arabisasi). Metode yang digunakan adalah library research dengan menganalisis dan mengelompokkan data-data primer. Analisis data dalam penelitian ini menggunakan pendekatan morfologis yaitu memfokuskan kepada istilahistilah budaya dalam majalah Alo Indonesia dengan memperhatikan masuknya unsur-unsur bahasa Asing ke dalam bahasa Arab dan mengganti lafaz-lafaz asing yang paling dekat dengan lafaz Arab. Hasil penelitian meliputi ketentuandan inkonsistensi ta'rib istilah-istilah budaya dan sumbangsih ketentuan ta'rib majalah Alo Indonesia.
\end{abstract}

Kata kunci: majalah Alo Indonesia, istilah-istilah budaya, ta'rib

\section{Abstract}

Alo Indonesia Magazine is an Arabic language magazine that contains a lot of cultural diversity information Indonesia. As an Arabic Magazine, there ara many vocabulary that there are no word in Arabic so it si necessary for ta'rib (Arabisation). The methode used is library research by analyzing and animating primary data. This research focused on the cultural terms in Alo Indonesia Magazine with regard to the inclusion of foreign laguage elements into Arabic and replace the foreign fhonemes closest to Arabic fhonemes. The results of the research include teh terms and inconsistency of ta'rib cultural terms and the offer provisions ta'rib.

Keywords: Alo Magazine Indonesia, cultural vocabulary, arabisation 


\section{PENDAHULUAN}

Bahasa dan budaya ibarat dua sisi uang logam yang hidup dan berevolusi sejalan dengan titah pergolakan zaman. Suatu budaya yang berkembang dan bersentuhan dengan dunia luar maka akan berdampak pada perkembangan suatu bahasa. Tidak terkecuali bahasa Arab yang terus berkembang berdampingan dengan kemajuan ilmu pengetahuan dan teknologi. Konvensi dari perkembangan suatu bahasa berembrio pada fenomena kebahasaan modern yang salah satu wujudnya adalah munculnya ragam kosa kata baru.

Fenomena kehadiran kosa kata baru yang muncul dalam suatu bahasa tidak terkecuali dalam bahasa Arab berkorelasi dengan peran dan kedudukan bahasa lain yang saling terhubung. Tampaknya fenomena ini merupakan perwujudan dari eksistensi suatu bahasa (Syuhada, 2011). Bahasa adalah anak kandung dari budaya yang senantiasa berkembang yang mana merupakan persinggungan dari berbagai suku dan bangsa yang ada di dunia. Semakin kuat benturan suatu budaya akan melahirkan realitas kebahasaan yang mana akan menyebabkan saling tercampurnya suatu bahasa dengan bahasa lain.

Salah satu wujud dari benturan kebudayaan itu disinyalir dari pesatnya kemajuan ilmu pengetahuan. Kemajuan ilmu pengetahuan yang begitu pesat tidak bisa tidak juga memiliki andil dalam perkembangan suatu bahasa. Patut juga diperhatikan bahwa pengetahuan yang makin pesat akan menjadi sia-sia belaka bila tidak ditopang oleh unsur-unsur penopang yang kuat. Perwujudan dari penopang itu adalah bahasa sebagai alat untuk menyampaikan pesan sekaligus sebagai penyambung lidah ilmu pengetahuan tanpa mengenal batasan ruang dan waktu (Gustini, 2016).

Fenomena perkembangan bahasa umumnya, khususnya bahasa Arab dalam menghadirkan kosa kata baru pada akhirnya memunculkan persoalan baru. Masalah ini menjadi pelik bila tidak dicarikan solusi cerdas, terukur dan terstruktur. Para pakar telah mencoba menjawab dengan mengidentifikasi kosa kata baru yang lahir dari benturan budaya dan memerlukan penamaan 
untuk temuan dalam kerangka ilmiah. Mengidentifikasi kosa kata baru belum dapat menjawab persoalan sehingga diperlukan ketentuan baru sehingga dapat dijadikan sebagai acuan dalam meracik kosa kata baru.

Meski sudah ada beberapa lembaga bahasa Arab yang telah melakukan proses ta'rib dengan menggunakan berbagai pendekatan dan metode. Ada banyak opsi yang ditawarkan oleh para pakar kebahasaan misalnya dengan cara menerjemahkan ke dalam bahasa ke-2, menjadikan kosa kata baru melalui kata serapan dan ada juga yang melakukan pendekatan linguistik dengan memperhatikan kaidah-kaidah baku (Malik, 2009).

Salah satu diantara sekian banyak lembaga bahasa yang melakukan proses ta'rib yaitu Lembaga Bahasa Arab di Kairo yang mana berdiri pada tahun 1351. Adapun tujuan didirikan lembaga ini adalah untuk membahas isu-isu kebahasaan dan menjaga keberlangsungan bahasa Arab. Hanya saja yang dilakukan oleh lembaga bahasa ini belum bisa mewakili secara umum ketentuan ta'rib dikarenakan masih ditemukan kekhasan sendiri (Amrullah, 2015).

Pembentukan kosa kata baru ini juga ditemukan dalam Majalah Alo Indonesia yang mana merupakan majalah yang konsisten mengenalkan budaya Indonesia kepada pembacanya baik dalam maupun luar negeri. Banyaknya istilah-istilah budaya Indonesia dalam majalah ini pada akhirnya menjadi sebuah keharusan bersinggungan dengan pembentukan kosa kata baru. Hal ini dikarenakan tidak adanya padanan istilah-istilah tersebut dalam bahasa Arab sehingga diperlukan sebuah ketentuan dan aturan khusus untuk diarabisasikan. Adapun diantara contoh istilah-istilah yang diarabkan dalam majalah Alo Indonesia adalah sebagai berikut:

$$
\begin{aligned}
& \text { Ambon : أمبون } \\
& \text { رمبانج : Rembang } \\
& \text { Cikarang: تشيكار انج : نشئج } \\
& \text { بينكولو : Bengkulu } \\
& \text { كتوبات لبار ان : Ketupat Lebaran } \\
& \text { كر ابان سابي : Karapan Sapi }
\end{aligned}
$$


Dari contoh di atas dapat diperhatikan bahwa proses pembentukan kosa kata baru yang diarabkan yang mana langsung bisa disesuaikan antara satu fonem dengan fonem lainnya. seperti kata "Ambon" diarabkan menjadi namun ada yang harus dikira-kira terlebih dahulu seperti kata Rembang, Cikarang dan Bengkulu. Fonem "c" dan "ng" tidak terdapat dalam bahasa Arab sehingga harus dicarikan fonem atau huruf yang memiliki kesamaan dengannya. Majalah Alo Indonesia di sini cenderung menggunakan fonem “c” dengan perpaduan huruf ت-ش تشيكار انج sehingga menjadi. Namun, kadangkadang fonem "c" juga bisa disamakan dengan huruf ش atau malah kadang dengan dengan huruf w. Begitu juga dengan pengguanaan "ng" dalam bahasa Arab disini Alo Indonesia menggunakan ن-ج sehingga "Rembang" menjadi رمبانجdan "Bengkulu” menjadi بينكولو. Namun, kadang-kadang “ng” tidak jarang juga ditransliterasikan dengan perpaduan huruf ن- ن atau kadangkadang menggunakan perpaduan huruf نك-

Sampai disini dapat disimpulkan ada beberapa problem atau masalah yang timbul dalam proses ta'rib dalam majalah Alo Indonesia. pertama, bagaimanakah sebenarnya ketentuan kaidah ta'rib yang ditawarkan oleh majalah Alo Indonesia. Kedua, sejauh manakah konsistensi majalah Alo Indonesia dalam men-ta'rib-kan istilah-istilah budaya Indonesia. Berangkat dari kedua masalah tersebut perlu kiranya untuk mendalami proses ta'rib dalam majalah Alo Indonesia dengan harapan memberikan sumbangan terhadap perkembangan bahasa Arab di Indonesia, khusunya pengenalan istilah-istilah budaya dalam bahasa Arab.

\section{METODE PENELITIAN}

Tulisan ini bermaksud memaparkan ta'rib kosa kata baru khususnya istilah-istilah budaya yang ada dalam majalah Alo Indonesia. Dalam menganalisis data-data yang ada digunakan pendekatan linguistik. Adapun pendekatan lingustik yang dimaksudkan adalah morfologi yang mana 
mengindentifikasi perubahan kosa kata atau istilah-istilah baru yang muncul dikarenakan faktor-faktor tertentu.

Objek material dalam kajian ini berupa kosa kata Arab baru yang terdapat dalam majalah Alo Indonesia khsususnya term istilah budaya Indonesia. Pemilihan objek material ini berdasarkan atas keunikan dan sumbangsih majalah tersebut dalam membentuk kosa kata istilah budaya baru dengan ketentuan atau aturan-aturan baru. Selain itu, peranan yang cukup besar dalam mengenalkan keanekaragaman budaya Indonesia secara masif dan berkelanjutan.

Dalam menganalisis objek material diawali dengan pengelompokkan data-data primer yang ada dalam majalah Alo Indonesia lalu dianalisis dengan pendekatan morfologi. Kategori penelitian termasuk ke dalam pendekatan kualitatif dan dideskripsikan secara sistematis.

\section{PEMBAHASAN}

\section{Pembentukan Kosa Kata Baru Bahasa Arab}

Sebagaimana yang telah disinggung diawal bahwa pembentukan kosa kata baru bahasa Arab atau ta'rib merupakan proses mencari padanan kata suatu bahasa ke dalam bahasa Arab. Meski kadang juga dimaksudkan sebagai proses menerjemahkan atau penyesuaian lafaz-lafaz yang saling berdekatan (Hadi, 2002). Tapi, perlu juga dipahami terlebih dahulu makna asal dari ta'rib yaitu merupakan kata kerja dari bahasa Arab yang berbentuk masdar.

Ta'rib juga dipahami sebagai proses memasukkan term suatu bahasa ke dalam leksem arab dengan berbagai pola, bisa dalam bentuk tașrif, mazid atau badal yang membentuk kosa kata arab baru (Ubaidillah, 2013). Pemahaman ta'rib disini menjawab persoalan fenomena kebahasaan yang hadir dari benturan kebudayaan dengan menggunakan pendekatan morfologi yaitu mengelompokkan yang kemudian dicari persamaan fonem dan bunyi dari leksem yang akan di-ta'rib-kan. Selain itu juga diadakan penambahan, 
pengurangan, penyisipan dan penghapusan huruf sehingga relevan dengan nătiq (penutur asli Arab).

Proses arabisasi berdasarkan beberapa lembaga bahasa dikategorikan ke dalam beberapa ketentuan:

1. Ketentuan mendasar yang melingkupi perubahan kosa kata dalam bentuk tașrif dan morfologis.

2. Harmonisasi gramatikal bahasa Arab.

Ketentuan mendasar pada poin di atas jamak digunakan oleh pakar bahasa kontemporer dalam melakukan proses arabisasi dan distandarkan dengan gramatikal Arab. Ketentuan mendasar dikerucutkan ke dalam variabel suara dan ketersusunan pola sehingga terbentuk suatu timbangan (wazan) sebagai acuan dasar perubahan fonem (Ubaidillah, 2013).

Arabisasi kosa kata Arab dari bahasa asing ini juga dibahas dalam kitab yang ditulis oleh Abdurahman Jalaluddin Al-Suyuti yang berjudul AlMuhzir fi 'ulumi al-Lughah wa anwa'iha. Ta'rib dalam kitab ini difahami sebagai kosa kata yang ditambahkan ataupun dikurangi hurufnya yang mana terjadi pada awalan dan akhiran dari kata dasar. Kadang awalan atau akhiran dari kata tersebut ditambahkan dengan 2 atau lebih fonem. Perubahan ini dilakukan agar terjadi kesesuaian dengan ketentuan penutur asli Arab (Amrullah, 2015). Sekilas hal ini mirip dengan pemahaman i'rab (ilmu tentang perubahan baris akhir suatu kata) dalam ilmu șaraf (ilmu tentang perubahan kata dalam bahasa Arab), namun disini dapat dipahami pola yang digunakan dalam pembentukan kosa kata baru adalah dengan menerapkan kaidah ilmu șaraf.

Proses perubahan kosa kata ke dalam bahasa Arab memiliki banyak model dan pola sehingga perlu dikelompokkan. Berikut ini model dan pola ta'rib yang dapat dirangkum: 
1. Pola dan Model Morfologis

Pola ini berdasarkan kepada struktur, klasifikasi dan bentuk dari kata yang akan di-ta'rib-kan. Dalam ranah linguistik pola ini disebut juga sebagai model pembentukan kata yang diawali dengan menyusun beberapa huruf dan membentuk satu atau beberapa kata. Setelah terjadi pembentukan beberapa kata, selanjutnya terbentuklah kalimat yang bisa dipahami dan mengandung pesan.

Studi morfologi lebih jauh dapat juga difahami sebagai rangkaian kata bermakna dan dapat dijadikan sebagai landasan pembentukan kalimat sesuai kaidah gramatikal yang benar. Selain itu, model morfologi dalam pembentukan kosa kata baru ini dalam ranah studi Ilmu Bahasa disebut juga sebagai ilmu alat atau saraf. Dalam kacamata ilmu Bahasa Arab klasik berarti bergelut dengan asal muasal dan perubahan suatu kata yang mana setiap perubahan memiliki arti yang berbeda-beda.

Dalam pergumulan ilmu șaraf penting juga dipahami adanya pengelompokkan sifat yang jamak dikenal dengan inflektif dan derivatif. Kedua sifat ini menjadi vital dan memegang peranan yang mendasar dalam membentuk suatu kata (Ridwan dan Hidayati, 2015). Secara sederhana inflektif dimaksudkan sebagai ketersuaian suatu kata jika dihadapkan dengan gramatikal bahasa Arab. Dalam ketersesuaian ini dihadapkan ke dalam afiks, prefiks, infiks dan juga sufiks. Kadang kala ketersesuaian ini dimaksudkan juga ke dalam bentuk kata kerja dan kata sifat. Dapat ditemukan pada kata memukul, dipukul dan terbaca sebagai bentuk kata inflektif dalam bahasa Indonesia (Chaer, 2007). Sedangkan dalam bentuk kata kerja selalu terkait dengan waktu dalam suatu kalimat yang mana dalam gramatika Arab populer dengan istilah fi'ilmặ̣i (kata kerja yang telah terjadi) dan muḍāri'(kata kerja yang sedang terjadi).

Derivasi dan infleksi memiliki perbedaan khusus yaitu pada kelas kata dan unsur leksikal. Derivasi menyebabkan perubahankelas kata yang terangkai dalam leksikal ke leksikal yang lain. Sedangkan infleksi tidak 
menyebabkan terjadinya perubahan pada kelas kata namun tetap dalam satu leksikal (Lutfi, 2012).

2. Penyerapan

Pola lain dalam pembentukan kosa kata Arab yang baru adalah penyerapan kata. Penyerapan kata berangkat dari tataran fonologis yang mana didekatkan bunyinya dan disesuaikan dengan nătiq Arab. Selain melakukan penyesuaian dengan penutur asli Arab juga dilakukan proses penyesuaian morfologis:

- Dalam kata kerja bahasa Inggris terdapat akhiran ist dan er, maka dalam kacamata morfologis hal ini bisa disesuaikan dengan cara menambahkan akhiran kata Arab dengan ya' nisbah.

- Selain akhiran ist dan er, persoalan ini juga ditemukan dalam akhiran kata sifat yaitu pada an, ic, al, ive. Adapun yang harus disesuaikan dalam morfologi arab dengan melakukan hal yang sama seperti yang dilakukan dalam kata kerja yaitu membubuhi ya' nisbah.

Pola penyerapan ini juga bisa dilakukan dengan pendekatan fonologis yang mana berangkat dari ketersuaian dengan penutur asli Arab sehingga terbentuklah kata dasar. Setelah terbentuk satu kata baru dilanjutkan dengan memperhatikan tataran mofologis dan juga sintaksis yang distandarkan dengan kaidah baku bahasa Arab (Hadi, 2002).

\section{Terjemahan}

Selanjutnya dalam pembentukan kosa kata baru bahasa Arab ditemukan juga pola terjemahan. Dalam pola ini jamak dilakukan dengan membubuhi 'iyyah' pada akhiran suatu kata asing misalnya pada akhiran 'ism' dan 'ics'. Penting juga dipahami bahwa model ini kadang juga digunakan pada perfiks dan sufiks. Setelah ditambahkan perfik dan juga 
sufiks pada salah satu kata lalu dirangkai beberapa kata sehingga menjadi kosa kata baru dalam bahasa Arab.

\section{Kosa Kata Baru}

Pola pembentukan kosa kata baru terakhir adalah pembentukan istilah baru. Dalam pola ini diawali dengan merubah dan menyesuaikan timbangan kata seperti yang ada dalam ilmu șaraf. Dalam studi ilmu s)araf timbangan kata berfungsi sebagai penunjuk keterangan tempat, alat dan waktu.

Setelah terjadi kesesuaian dengan timbagan kata dan dibentuklah kata baru yang disesuaikan dengan kaidah morfologis bahasa Arab. Dalam konteks morfologis dilakukan perubahan berupa afiksasi seperti sirkumfiks, afik. Pada akhirnya kosa kata baru ini terjadi setelah terangkainya perfiks dan sufiks.

\section{Ketentuan Ta'rib Majalah Alo Indonesia}

Pada bagian ini akan dipaparkan ketentuan ta'rib dalam majalah Alo Indonesia. ketentuan ta'rib dalam majalah ini terjadi melalui proses mendekatkan dan menyamakan fonem dengan penutur asli Arab. Setelah dicermati proses ta'rib dalam majalah Alo Indonesia dengan mengganti fonem yang paling dekat dengan fonem bahasa Arab. Berikut ketentuan ta'rib fonem bahasa Indonesia dalam majalah Alo Indonesia dari alfabet A-Z1 .

\section{a) Ta'rib fonem $\mathrm{A}$}

Angklung merupakan nama alat musik tradisional yang ada di Indonesia. sedangkan "Ambon" dan "Ambalat' adalah nama kota dan pulau yang ada di Indonesia. Istilah "Angklung”, “Ambon” dan "Ambalat” belum memiliki padanan dalam bahasa Arab. Majalah Alo Indonesia mengambil kata-kata di atas menjadi kosa kata baru. Kosa kata baru tercipta sebagai akibat dari ketersuaian dan mendekatkan bunyi fonem "a". Maka di sini akan

${ }^{1}$ Majalah Alo Indonesia edisi 2010-2011. 
fokuskan dulu dari huruf "a". Dalam bahasa Arab huruf "a" lebih dekat lafaznya dengan huruf hamzah أ. Jadi, huruf "a" hampir tidak memiliki kesulitan ketika di-ta'rib-kan.

b) Ta'rib fonem B

Kata "Bandung", "Bojonegoro" dan "Banyuwangi" di atas telah mengalami proses ta'rib di dalam majalah Alo Indonesia. Jika kita perhatikan fonem "b" pada kata tersebut disamakan dengan huruf "“لباء". Hal ini dikarenakan adanya kesamaan lafaz الباء dengan fonem “b”. Sehingga ta'rib fonem 'b" tidak memiliki kesulitan ketika menjadi kalimat mu'arrobah.

c) $\mathrm{Ta}$ 'rib fonem $\mathrm{C}$

Fonem "c" pada kalimat "Cirebon", "Ciputat" dan "Cibubur" dalam majalah Alo Indonesia telah melalui proses Ta'rib. Namun, fonem "c" dalam bahasa Arab tidak memiliki persamaan lafaz dalam huruf Arab. Namun, dalam majalah Alo Indonesia fonem "c" di-ta'rib-kan dengan menggabungkan huruf الثين dengan huruf التاء. Hal ini disebabkan karena fonem "c" apabila di-ta'rib-kan akan mengalami asimilasi fonemik. Sehingga fonem “c” apabila di-ta'rib-kan menjadi " تش “.

d) Ta'rib fonem D

Fonem "d" dalam kata "Depok", "Denpasar", dan "Dayak" di atas telah mengalami ta'rib dalam majalah Alo Indonesia. Adapun fonem "d" memiliki kesamaan lafaz dengan huruf "الدال". Sehingga tidak memiliki kesulitan lagi ketika di-ta'rib-kan kedalam bahasa Arab.

\section{e) Ta'rib fonem $\mathrm{E}$}

Fonem "e" tidak terdapat dalam bahasa Arab. Namun fonem "e" memiliki kemiripan dengan huruf “佔” dengan menambahkan harakat kasrah atau dengan menambahkan huruf (ي) sukun. Walaupun sesungguhnya tidak sama persis, tapi ini cukup mewakili fonem "e" dalam bahasa Arab. Hal ini 
juga yang dipakai dalam majalah Alo Indoensia dalam men-ta'rib-kan fonem "e".

f) Ta'rib fonem $\mathrm{F}$

Fonem "f" dalam bahasa Indonesia memiliki kesamaan dengan huruf “ف dalam bahasa Arab. Pen-ta'rib-an fonem "f” ini tidaklah memiliki kesulitan. Karena memiliki padanan yang setara antara bahasa Indonesia dan bahasa Arab.

\section{g) Ta'rib fonem $\mathrm{G}$}

Fonem "g" dalam bahasa Arab pada dasarnya tidak memiliki padanan yang sama persis. Namun, dalam majalah Alo Indonesia di-ta'rib-kan dengan huruf “غُ lafaz berdekatan. Fonem "g” lebih dekat lafaznya dengan huruf " $\dot{\xi}$ ” sehingga hampir dipastikan tidak menemui kesulitan dalam mencari padanan ketika dita'rib-kan. Namun, dikarenakan adanya kebiasaan orang Arab khususnya bahasa Arab Ammiyah (bahasa Arab tidak formal) di beberapa daerah mengganti huruf " dalam majalah Alo Indonesia juga cenderung menggunakan huruf "ج" sebagai ta'rib fonem "g".

\section{h) Ta'rib fonem $\mathrm{H}$}

Fonem "h" dalam bahasa Indonesia, dalam majalah Alo Indonesia dita'rib-kan menjadi huruf " $ح$ ” dan “o". Karena pada dasarnya kedua huruf tersebut memiliki kesamaan lafaz dengan fonem "h". Jadi, tidak memiliki kesulitan dalam men-ta'rib-kan fonem " $\mathrm{h}$ " tersebut.

\section{i) $T a$ 'rib fonem I}

Fonem "i" dalam majalah Alo Indonesia di-ta'rib-kan dengah huruf “|”. Pada dasarnya fonem “ $\mathrm{i}$ ” memiliki kesamaan ketika di-ta'rib-kan dengan fonem "e" dengan menambahkan huruf "ي" sukun atau kasrah. Karena dalam 
bahasa Arab yang tidak mengenal fonem "e" maka disamakan dengan fonem "i".

\section{j) Ta'rib fonem $\mathbf{J}$}

Fonem “j” ketika di-ta'rib-kan tidak memiliki kesulitan. Adapun lafaz yang sama dengan fonem “j” yaitu huruf "ج". sehingga men-ta'rib-kan fonem “j” kita bisa langsung menggunakan huruf "ج" tanpa harus difikir lagi.

k) Ta'rib fonem $\mathrm{K}$

"Karo", "Kertosono" dan Kusuma Bangsa telah mengalami proses ta'rib dalam majalah Alo Indonesia. Kalau diperhatikan fonem "k" di-ta'ribkan dengan menggunakan huruf "ك"ك". Karena yang mirip dengan fonem "k" adalah huruf “s".

1) Ta'rib fonem $\mathrm{L}$

Dalam kosa kata "Lamongan" fokus pada fonem L. Kata Lamongan adalah sebuah nama kota yang terdapat di wilayah propinsi Jawa Timur. Sedangkan "Lenong" dan "Lubis" adalah nama kesenian tradisional dan marga yang berasal dari Sumatera Utara. Kata "Lamongan", "Lenong" dan "Lubis" kalau dapat perhatikan ada fonem "l” yang mana dalam majalah Alo Indonesia di-ta'rib-kan dengan menggunakan huruf "J". Karena fonem "l" memiliki kemiripan lafaz dengan huruf "J". Sehingga tidak memiliki kesulitan ketika di-ta'rib-kan.

\section{m) Ta'rib fonem M}

Fonem "m" dalam kata "Madura", "Mojokerto" dan "Malang" dalam majalah Alo Indonesia di-ta'rib-kan dengan huruf "ק". Karena huruf "ק" memiliki kesamaan lafaz dengan fonem " $m$ ". Sehingga tidak ditemui kesulitan dalam men-ta'rib-kan fonem "m". 
n) Ta'rib fonem $\mathrm{N}$

Fonem "n" dalam kata "Nias", "Nagari Sembilan" dan "Nangro Aceh Darussalam” dalam majalah Alo Indonesia di-ta'rib-kan dengan huruf "ن". karena fonem "n" sangat berdekatan secara lafaz dengan huruf "ن".

o) Ta'rib fonem $\mathrm{O}$

Selanjutnya ditemukan kata "OKO” yang mana kata ini adalah sebuah kata yang dipakai untuk menamai salah satu kabupaten yang berada di bawah naungan Pemerintahan Propinsi Sumatera Selatan. Sedangkan "Ondel-Ondel” dan "Oasis" merupakan nama kesenian Betawi dan nama tempat. Kalau kita perhatikan dengan seksama fonem "o" di-ta'rib-kan dengan huruf "cl”. Hal ini dikarenakan tidak adanya padanan yang mirip dengan fonem "o" tapi yang lebih mendekati adalah "“" dengan menambahkan huruf "و" sukun atau baris dommah. Jadi, dalam men-ta'rib-kan fonem "o" majalah Alo Indonesia menggunakan huruf "g".

\section{p) $T a$ 'rib fonem $P$}

Fonem "p" dalam kata "Papua", "Purabaya" dan "Purwokerto" dita'rib-kan dengan huruf "ب". Hal ini dikarenakan tidak ditemukannya padanan fonem "p" dalam bahasa Arab tapi lebih dekat dengan huruf "ب" dan kebiasaan lidah orang Arab yang susah ketika menggunakan fonem "p". Sehingga dalam majalah Alo Indonesia cenderung men-ta'rib-kan fonem " $\mathrm{p}$ " dengan huruf "ب"

\section{q) Ta'rib fonem Q}

Fonem "q" seperti di-ta'rib-kan dengan huruf "ق" karena memang secara lafaz antara fonem "q" dengan huruf "ق" berdekatan. Sehingga majalah Alo Indonesia dalam men-ta'rib-kan fonem "q" dengan menggunakan huruf "ق". 
r) Ta'rib fonem $\mathrm{R}$

Rendang merupakan makanan khas dari Sumatera Barat. Sedangkan "Rindu Alam" dan "Ragunan" merupakan nama rumah makan dan nama daerah yang ada di Indonesia. Fonem "r" pada kata "Rendang", "Rindu Alam" dan "Rangunan" di-ta'rib-kan dengan menggunakan huruf "ر". Karena pada dasarnya fonem "r" memiliki kesamaan lafaz dengan huruf " $\jmath$ ". Sehingga majalah Alo Indonesia menggunakan huruf " $\jmath$ " dalam men-ta'ribkan fonem " $r$ ".

\section{s) Ta'rib fonem $\mathrm{S}$}

Fonem "s" dalam kata "Surabaya", "Sibayak" dan "Sinabung" dita'rib-kan dengan huruf "w". Hal ini dikarenakan karena adanya kedekatan lafaz antara fonem "s" dengan "w". Sehingga majalah Alo Indonesia dalam men-ta'rib-kan fonem "s" menggunakan huruf "w".

\section{t) Ta'rib fonem $\mathrm{T}$}

"Ternate", "Tidore" dan "Tolire" merupakan nama-nama kota di Indonesia. fonem " $\mathrm{t}$ " pada kata "Ternate", "Tidore" dan "Tolire" di-ta'ribkan dengan menggunakan huruf "ت". Karena adanya kesamaan lafaz antara fonem "t" dengan huruf "ت". Sehingga dalam majalah Alo Indonesia menggunakan huruf "ت" dalam men-ta'rib-kan fonem " $\mathrm{t}$ ".

\section{u) Ta'rib fonem $\mathrm{U}$}

Fonem "u" dalam di-ta'rib-kan dengan menggunakan huruf "w)" dengan menambahkan huruf " $g$ " atau baris dommah. Pada dasarnya tidak ada kesulitan dalam men-ta'rib-kan fonem "u".

v) $T a$ 'rib fonem $\mathrm{V}$

Fonem "v" dalam majalah Alo Indonesia di-ta'rib-kan dengan menggunakan huruf "ف". Hal ini hampir mirip dengan fonem "f” dikarenakan 
antara fonem "f" dan "v" juga memiliki kesamaan lafaz. Sehingga dalam majalah Alo Indonesia ta 'rib fonem "v" disamakan dengan fonem " $\mathrm{f}$ ".

w) Ta'rib fonem $\mathrm{W}$

Fonem "w" dalam majalah Alo Indonesia di-ta'rib-kan dengan huruf "و". Hal ini dikarenakan adanya kemiripan antara fonem "w" dengan huruf “و”. Dalam fonem “w” ini tidak ditemukan kesulitan ketika di-ta'rib-kan.

x) $T a$ 'rib fonem $\mathrm{X}$

Dalam bahasa Arab tidak ditemukan padanan kata fonem " $x$ ". Namun dalam majalah Alo indonesia fonem " $\mathrm{x}$ " di-ta'rib-kan dengan menggabungkan dua huruf yaitu "كس".

y) $T a ' r i b$ fonem $\mathrm{Y}$

Fonem "y" dalam kata diatas di-ta'rib-kan dengan menggunakan huruf “ي”. Karena fonem “y” memiliki kesamaan lafaz dengan huruf “ي”.

z) Ta'rib fonem $\mathrm{Z}$

Dalam men-ta'rib-kan fonem “z” majalah Alo Indonesia menggunakan huruf “ $j$ " karena memang keduanya memiliki lafaz yang berdekatan. Sehingga tidak ada kesulitan dalam proses $t a$ 'rib tersebut.

\section{Inkonsistensi Ketentuan Ta'rib dalam Majalah Alo Indonesia}

Dalam majalah Alo Indonesia ada beberapa bentuk ta'rib yang tidak konsisten. Adapun diantara bentuk inkonsistensi ta'rib dalam majalah Alo Indonesia sebagai berikut ${ }^{2}$ :

a. Penggunanaan fonem "c" dalam majalah Alo Indnesia

Setelah penulis adakan penelitian lebih lanjut, penulis menemukan inkonsistensi penggunaan fonem " $c$ " yang beraneka ragam. Hal ini dapat kita perhatikan pada kosa kata yang ada dalam tabel berikut :

\footnotetext{
${ }^{2}$ Bundelan Majalah Alo Indonesia Edisi 2010-2011.
} 
Tabel 1 Contoh Kata Ta'rib dengan Fonem “c”

\begin{tabular}{|c|c|c|}
\hline No & Indonesia & Ta'rib \\
\hline 1 & Aceh & أتشيه \\
\hline 2 & Cirebon & تشيربون \\
\hline 3 & Cikuning & تثشيكونينج \\
\hline
\end{tabular}

Sumber: Majalah Alo Indonesia Edisi Desember 2010. Hlm. 5-6

Tabel 2 Contoh Kata Ta'rib dengan Fonem “c”

\begin{tabular}{|c|c|c|}
\hline No & Indonesia & Ta'rib \\
\hline 1 & Merci & ميرسي \\
\hline 2 & City Bank & سيتي بنك \\
\hline 3 & Central Park Mall & سنتر ال بارك مول \\
\hline
\end{tabular}

Sumber: Majalah Alo Indonesia Edisi Juli-Agustus 2010. Hlm. 4-5

Tabel 3 Contoh Kata Ta'rib dengan Fonem “c”

\begin{tabular}{|c|c|c|}
\hline No & Indonesia & Ta'rib \\
\hline 1 & Cianjur & شائنجنجور \\
\hline 2 & Canting & شيكمبار \\
\hline 3 & Cikembar & . \\
\hline
\end{tabular}

Sumber: Majalah Alo Indonesia Edisi Juni 2011. Hlm. 12-13

Dari ketiga tabel di atas dapat diperhatikan secara seksama bahwa ada tiga bentuk ta'rib fonem "c" dalam majalah Alo Indonesia yaitu dengan menggunakan "تش", “" dan “" "ش". Pada hakikatnya ketiga lafaz tersebut sesungguhnya memiliki kedekatan dengan fonem "c". Sehingga ketiga lafaz tersebut dapat digunakan sebagai bentuk ta'rib fonem "c". Tapi, majalah Alo Indonesia di sini lebih banyak menggunakan lafaz تش dalam men-ta'rib-kan fonem "c". Dari beberapa data diambil kesimpulan bahwa untuk lebih konsisten dalam proses ta'rib fonem "c" adalah dengan menggunakan "تش" sehingga lebih bisa untuk diseragamkan.

b. Penggunaan fonem "g" dalam majalah Alo Indonesia

Selain fonem "c" juga terdapat inkonsistensi pada fonem "g". Adapun untuk melihat bentuk inkonsitensi dari fonem "g" dengan memperhatikan tabel berikut. 
Tabel 4 Contoh Kata Ta'rib dengan Fonem “g”

\begin{tabular}{|c|c|c|}
\hline No & Indonesia & Ta'rib \\
\hline 1 & Imogiri & أيموجيري \\
\hline 2 & Agung & أجونجا أسا جايا \\
\hline 3 & Agesa Asa ya \\
\hline
\end{tabular}

Sumber: Majalah Alo Indonesia Edisi Oktober-November 2010. Hlm. 5-6

Tabel 5 Contoh Kata Ta'rib dengan Fonem "g"

\begin{tabular}{|c|c|c|}
\hline No & Indonesia & Ta'rib \\
\hline 1 & Bogor & أغونج| \\
\hline 2 & Agung & ادينوكوسوما غوناويجايا \\
& Haryono & \\
& Kusuma & \\
\hline 3 & Adi Guna & \\
\hline
\end{tabular}

Sumber: Majalah Alo Indonesia Edisi Januari-Februari 2010. Hlm. 4-5

Tabel 6 Contoh Kata Ta'rib dengan Fonem “g”

\begin{tabular}{|c|c|c|}
\hline No & Indonesia & Ta'rib \\
\hline 1 & Jogjakarta & سوكجاكارتار اكت \\
\hline 2 & Singkarak & Gونتور \\
\hline 3 & Gontor & \multicolumn{2}{|l}{} \\
\hline
\end{tabular}

Sumber: Majalah Alo Indonesia Edisi Oktober-November 2010. Hlm. 3-4

Dari ketiga tabel di atas dapat diperhatikan secara seksama bahwa ada tiga bentuk ta'rib fonem "g" dalam majalah Alo Indonesia yaitu dengan

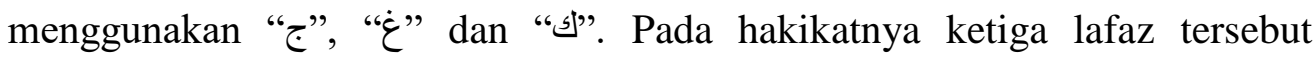
sesungguhnya memiliki kedekatan dengan fonem "g". Sehingga ketiga lafaz tersebut dapat digunakan sebagai bentuk ta'rib fonem "g". Tapi, majalah Alo Indonesia lebih banyak menggunakan lafaz ج dalam men-ta'rib-kan fonem "g". Dari beberapa data tersebut ditarik kesimpulan bahwa untuk lebih konsistennya ta'rib fonem "g" adalah dengan menggunakan "ج" sehingga lebih bisa diseragamkan. 
c. Penggunaan fonem rangkap "ng" dalam majalah Alo Indonesia

Dalam bahasa Indonesia ada fonem rangkap seperti "ng”. Dalam majalah Alo Indonesia proses ta'rib "ng" ini juga mengalami inkonsistensi sebagaimana yang termaktub dalam tabel berikut.

Tabel 7 Contoh Kata Ta'rib dengan Fonem Rangkap "ng”

\begin{tabular}{|c|c|c|}
\hline No & Indonesia & Ta'rib \\
\hline 1 & Aceng & أتشينج \\
\hline 2 & Abing & أبينج \\
\hline 3 & Agung & (أجونج \\
\hline
\end{tabular}

Sumber: Majalah Alo Indonesia Edisi Mei-Juni 2011. Hlm. 5-6

Tabel 8 Contoh Kata Ta'rib dengan Fonem Rangkap "ng”

\begin{tabular}{|c|c|c|}
\hline No & Indonesia & Ta'rib \\
\hline 1 & Bandung & باندونغ \\
\hline
\end{tabular}

Sumber: Majalah Alo Indonesia Edisi Januari-Februari 2011. Hlm. 3-4

Dari tabel di atas kalo diperhatikan secara seksama ada dua macam bentuk ta'rib dari fonem rangkap "ng" yaitu "نجن "نغ " Setelah mengumpulkan data-data terkait ta'rib fonem rangkap "ng" tersebut kedua jenis ta'rib tersebut sama-sama memiliki kemiripan lafaz. Namun, Alo Indonesia lebih banyak digunakan "نج". Sehingga untuk keseragaman penggunaan ta'rib fonem rangkap "ng” dengan lafaz "نج".

\section{Sumbangsih Ketentuan Ta'rib}

Setelah dipaparkan, dipelajari dan diamati data-data terkait ta'rib istilah budaya dalam majalah Alo Indonesia adalah dengan mendekatkan lafaz dan fonem yang saling berdekatan atau saling memilki kesamaan bunyi. Sehingga satu sisi tidak menyebabkan kesulitan bagi orang Arab asli, sisi lain juga membantu mempopulerkan istilah-istilah budaya Indonesia ke dalam kancah Internasional.

Selain itu, perlu ditekankan bahwa penyusunan dan pembentukan proses ta'rib dalam majalah Indonesia berangkat dari menyepadankan 
kesamaan fonem, sehingga menjadi sumbangan majalah Alo Indonesia khususnya dalam $t a$ 'rib fonetik.

Berangkat dari pengkajian kosa kata istilah budaya yang ada dalam majalah Alo Indonesia maka disimpulkan suatu pedoman ta'rib seperti yang ada dalam tabel berikut:

Tabel 9 Ta'rib Fonetik dalam Majalah Alo Indonesia

\begin{tabular}{|c|c|c|c|c|c|}
\hline No & Alfabet & Ta'rib & No & Alfabet & Ta'rib \\
\hline 1 & $\mathrm{~A}$ & i & 14 & $\mathrm{~N}$ & ن \\
\hline 2 & B & ب & 15 & $\mathrm{O}$ & أو \\
\hline 3 & $\mathrm{C}$ & تش & 16 & $\mathrm{P}$ & ب \\
\hline 4 & D & د & 17 & Q & ق \\
\hline 5 & $\mathrm{E}$ & إي & 18 & $\mathrm{R}$ & נ \\
\hline 6 & $\mathrm{~F}$ & ف & 19 & $\mathrm{~S}$ & س \\
\hline 7 & G & ج & 20 & $\mathrm{~T}$ & ت \\
\hline 8 & $\mathrm{H}$ & $\tau-0$ & 21 & $\mathrm{U}$ & أو \\
\hline 9 & I & إي & 22 & V & ف \\
\hline 10 & $\mathrm{~J}$ & ج & 23 & $\mathrm{~W}$ & 9 \\
\hline 11 & K & 5) & 24 & X & كس \\
\hline 12 & $\mathrm{~L}$ & J & 25 & $\mathrm{Y}$ & ي \\
\hline 13 & $\mathrm{M}$ & ? & 26 & $\mathrm{Z}$ & j \\
\hline
\end{tabular}

Selain fonem di atas dalam ta'rib juga ditentukan cara men-ta'rib-kan fonem rangkap bahasa indonesia yaitu:

Tabel 10 Ta'rib Fonem dalam Majalah Alo Indonesia

\begin{tabular}{|l|c|c|}
\hline No & Alfabet Rangkap & Ta’rib \\
\hline & $\mathrm{Ng}$ & $\underset{ }{ }$ \\
\hline
\end{tabular}




\section{PENUTUP}

Setelah melakukan pengkajian dan penelitian terhadap majalah Alo Indonesia yaitu arabisasi kosa kata istilah-istilah budaya, dapat disimpulkan ketentuan ta'rib dalam majalah Alo Indonesia adalah dengan mendekatkan lafaz-lafaz bahasa Indonesia dengan bahasa Arab. Seperti berdekatannya huruf "أ " dengan fonem "a", huruf ب dengan fonem "b", huruf $ت$ denga fonem " $t$ " dan seterusnya.

Jika tidak ditemukan fonem yang berdekatan maka bisa dilakukan dengan melihat kebiasaan orang arab seperti fonem "p" yang tidak terdapat dalam bahasa Arab. Namun, adanya kebiasaan lidah orang Arab menggunakan huruf $ب$ untuk mewakili fonem "p".

Selain itu juga ditemukan bentuk inkonsistensi ta'rib dalam majalah Alo Indonesia misalnya pada fonem "c" dengan ta'ribnya تش-ش- , "g" dengan bentuk ta'ribnya ج ج-غ dan fonem rangkap "ng" dengan bentuk ta'rib-nya نج-نغ. Untuk lebih seragamnya ketentuan ta'rib ini penulis mengambil kesimpulan dengan melihat kecendrungan dan lebih banyaknya penggunaan dari masing-masing bentuk inkonsistensi tersebut yaitu تش untuk fonem "c", ج ج untuk fonem "g" dan untuk fonem rangkap "ng".

Pada akhirnya, tulisan ini mencoba menyusun sumbangsih pedoman ketentuan ta'rib berdasarkan temuan yang ada dalam majalah Indonesia. diharapkan dengan sumbangsih pedoman ketentuan ta'rib bisa memudahkan para pemerhati bahasa dan budaya dalam menyeragamkan istilah-istilah baru yang hendak di-ta'rib-kan. 


\section{DAFTAR PUSTAKA}

Amrullah, Muhammad Afif. 2017. "Analisis Perubahan Fonologis dalam Pembentukan Kalimat Mu'arabah" dalam Jurnal Adabiyat, Vol. 4 No. 2. hlm. 217-226.

Bundelan Majalah Alo Indonesia. Edisi 2010-2011.

Chaer, A. 2007. Linguistik Umum. Jakarta: Rineka Cipta.

Gustini, N. 2016. "Bimbingan dan Konseling melalui Pengembangan Akhlak Mulia Siswa Berbasis Pemikiran Al-Ghazali" dalam Tadris: Jurnal Keguruan dan Ilmu Tarbiyah, Vol. 1, No. 1. hal. 1-14.

Hadi, S. 2002. "Berbagai Ketentuan Baru dalam Ta'rib: Pembahasan Seputar Perkembangan Mutakhir dalam Bahasa Arab" dalam Humaniora, Vol. 16. No. 1. hlm. 77-85.

Lutfi, K. M. 2012. “Afiksasi sebagai Upaya Integrasi antara Teori Tasrfi alAf'al Klasik dengan Morfologi Modern" dalam Jurnal Islamic Review, Vol.1, No. 1. hlm. 17-47.

Malik, A. 2009. “Arabisasi (Ta'rib) dalam Bahasa Arab (Tinjauan DeskriptifHistoris)" dalam Adabiyyat, Vol. 8, No. 2. hlm. 261-276.

Ubaidillah, I. 2013. "Kata Serapan Bahasa Asing dalam al-Qur'an dalam Pemikiran at-Thabari" dalam Jurnal At-Ta'dib, Vol. 8, No. 1. hlm. 119-132.

Syuhada, A. 2012. "Sistem Nomina Morfologi Variabel (Isim Mutasharrif) Bahasa Arab" dalam Jurnal At-Ta'dib, Vol. 6, No. 2. hlm. 269-289. 